\title{
Jenis-Jenis Bintang Laut Dan Bulu Babi (Asteroidea, Echinoidea: Echinodermata) Di Perairan Pulau Cilik, Kepulauan Karimunjawa
}

\author{
Retno Hartati, Endika Meirawati, Sri Redjeki, Ita Riniatsih, dan R.T. Mahendrajaya
}

\author{
Departemen IImu Kelautan, Fakultas Perikanan dan IImu Kelautan, Universitas Diponegoro \\ Jl. Prof. Soedarto, SH. Tembalang, Semarang 50275 \\ Email : retnohartati.undip@yahoo.com
}

\begin{abstract}
Types of Star Fish and Sea Urchins (Asteroidea, Echinoidea: Echinodermata) In Cilik Island, Karimunjawa Waters
\end{abstract}

Echinoderms are fundamentally good indicators of health and status of coralline communities in marine waters. Substrat of sandy, rububle and coral reefs are good habitat for Asteroidea dan Echinoidea. This study aim to identify sea star (Asteroidea) and sea urchin (Echinoidea) species from Pulau Cilik waters of Karimunjawa Islands. Asteroidea and Echinoidea observed using the line transect method used, ie subjects within the same distance between the transect and the transect square with observations of $2.5 \mathrm{~m}$ on the right and left of transect line line. Morphology, habitat type (substrate \& depth) and total number of sea stars and sea urchins at each station were determined. The results showed that Pulau Cilik has six species of Asteroidea (Sea star), ie Linckia laevigata, L. multifora, Neoferdifla ocellata (Family Ophidiasteridae), Luidia alternate (Luidiidae Family), Culcita novaeguineae (Family Oreasteridae) and Acanthaster planci which belongs to Family Acanthasteridae. There were 4 species of Echinoidea Sea urchin) found, i.e. Diadema setosum, D. antillarum, D. savignyi and Echinothrix calamaris, which all were family members of Diadematidae

Keywords: Ophidiasteridae, Luidiidae, Oreasteridae, Acanthasteridae, Diadematidae

\begin{abstract}
Abstrak
Echinodermata pada dasarnya merupakan indikator kesehatan dan status dari terumbu karang di laut. Dasar perairan yang landai dengan substrat pasir, terumbu karang dan pecahan karang yang merupakan habitat bagi hewan jenis Asteroidea dan Echinoidea. Penelitian ini bertujuan untuk mengidentifikasi henis-jenis bitang laut dan bulu babi dari perairan Pulau Cilik, Kepulauan Karimunjawa. Pengamatan Asteroidea dan Echinoidea menggunakan metoda line transect yang dimodifikasi, yaitu mengamati subjek dalam jarak yang sama sepanjang garis transect dan kuadrat transect dengan pengamatan $2,5 \mathrm{~m}$ di sebelah kanan dan kiri garis line transect. Morfologi, tipe habitat (substrat \& kedalaman) dan jumlah total bintang laut dan bulu babi di tiap stasiun dicatat selanjutnya sampel diidentifikasi berdasarkan ciri morfologi tersebut. Hasil penelitian menunjukkan bahwa di perairan Pulau Cilik ditemukan enam spesies Asteroidea (Bintang Laut), yaitu Linckia laevigata, L. multifora, Neoferdifla ocellata (Famili Ophidiasteridae), Luidia alternate (Famili Luidiidae), Culcita novaeguineae (Famili Oreasteridae) dan Acanthaster planci yang termasuk dalam Famili Acanthasteridae. Species Echinoidea (Bulu Babi) ditemukan 4 spesies Diadema setosum, D. antillarum, D. savignyi dan Echinothrix calamaris semua anggota famili Diadematidae.
\end{abstract}

Kata kunci : Ophidiasteridae, Luidiidae, Oreasteridae, Acanthasteridae, Diadematidae 


\section{PENDAHULUAN}

Kepulauan Karimunjawa merupakan wilayah dengan tipe ekosistem terumbu karang, padang lamun, hutan mangrove dan ekosistem daratan berupa hutan tropis dataran rendah. Hal ini menjadikan Kepulauan Karimunjawa mempunyai tiga potensi sebagai kawasan konservasi, wisata dan perikanan yang keutuhan dan kelestariannya harus tetap dijaga. Pulau Cilik sebagai salah satu pulau di Kepulauan Karimunjawa yang memiliki kondisi terumbu karang yang cukup baik, namun masih sedikit penelitian dilakukan di lokasi tersebut. Diantara biota laut yang terdapat di Pulau Cilik adalah Echinodermata, yang merupakan komponen penting pada ekosistem terumbu karang (Bellwood et al., 2004). Menurut Alvarado et al (2012) tingginya keanekaragaman eechinodermata mengindikasikan tingginya biodiversitas terumbu karang. Fauna Asteroidea dan Echinoidea yang termasuk kedalam fauna Echinodermata merupakan biota penghuni ekosistem terumbu karang yang keberadaan dan peranannya cukup menonjol (Birkeland, 1989). Kebiasaan hidup, predasi dan kompetisi mempengaruhi kelimpahan Asteroidea dan Echinoidea di suatu tempat, disamping faktor lingkungan yang saling berkaitan.

Sistem ekologi, faktor abiotik, dan biotik saling terkait, dan berinteraksi dengan lainnya. Menurut Chenelot et al., (2009) pengetahuan tentang distribusi echinodermmata dalam hubungannya dengan ruang dan waktu akan membantu mendapatkan pengetahuan tentang ekosistem pesisir.

Bintang Laut merupakan anggota dari kelas Asteroidea (filum Echinodermata) secara ekologis berperan sangat penting bagi ekosistem laut. Kelas Asteroidea ini mempunyai species yang paling tinggi pada filum echinodermata, yaitu hampir 1900 species yang masuk dalam 36 famili dan 370 genera di dunia (Mah dan Blake, 2012). Bintang laut dapat hidup pada semua kedalaman dari intertidal sampai abisal dan bisa ditemukan diseluruh perairan dunia, terutama daerah Atlantik tropis and wilayah Indo-Pacifik. Asteroidea merupakan biota yang cukup komersial, yaitu sebagai biota yang dipelihara dalam akuarium. Secara ekonomi, Asteroidea memiliki peranan penting sehubungan dengan perannya sebagai pemakan kerang yang dibudidaya (Barnes, 1980). Sedangkan menurut Arm dan Camp (1997) Asteroidea juga memakan karang.

Penelitian tentang keanekaragaman echinodermata di Kepulauan Karimunjawa pernah dilakukan oleh Azis dan Darsono (1999); Hadi et al. (2011) di Indonoor Wreck, Pulau Kemujan; Dian et al. (2005) tentang sand dollar (Echinoidea) di Pulau Cemara besar serta Mu'arif (2009), Suryanti et al. (2016) dan Asmoro et al., (2017) tentang sand dollar (Echinoidea) di Pulau Cemara kecil. Namun belum ada informasi tentang echinodermata di Pulau Cilik Kepulauan Karimunjawa. Berdasarkan pertimbangan tersebut perlu kiranya mempelajari kelimpahan biota jenis Asteroidea dan Echinoidea yang ada di perairan Pulau Cilik. Penelitian ini bertujuan untuk mengetahui komposisi jenis-jenis Asteroidea dan Echinoidea yang berasosiasi dengan ekosistem terumbu karang yang ada di Pulau Cilik Kepulauan Karimunjawa, Jepara. Diharapkan hasil penelitian ini dapat melengkapi penelitian-penelitian yang telah dilakukan sebelumnya

\section{MATERI DAN METODE}

Materi penelitian ini adalah jenis-jenis Asteroidea dan Echinoidea yang ditemukan di perairan Pulau Cilik Karimunjawa. Adapun metoda pengumpulan data yang dipakai adalah sample survey method. Lokasi penelitian adalah Pulau Kecil yang termasuk dalam kawasan Taman Nasional Karimunjawa, yang merupakan zona penyangga yang letaknya berdekatan dengan Pulau Tengah yang berfungsi sebagai zona inti dalam kawasan Taman Nasional Karimunjawa. Sehingga diasumsikan memiliki keterkaitan ekologis dengan Pulau Tengah sebagai zona inti

Pengamatan objek penelitian, Asteroidea dan Echinoidea menggunakan metoda line transect yang dimodifikasi, yaitu mengamati subjek dalam jarak yang sama 
sepanjang garis transect (Loya, 1978) dan kuadrat transect dengan pengamatan 2,5 m di sebelah kanan dan kiri garis line transect (Clark dan Rowe, 1971).

Pulau Cilik merupakan pulau yang relatif kecil, dengan luas \pm 2 Ha. Transek dilakukan di empat lokasi untuk masingmasing di sebelah barat, utara, timur, dan selatan pulau. Pemilihan empat lokasi tersebut bertujuan untuk mendapatkan hasil sampling yang bisa mewakili kondisi populasi Asteroidea dan Echinoidea pada Pulau Cilik. Pengambilan sampel dilakukan pada pagi hari saat pasang agar didapatkan kecerahan yang maksimal. Pada masingmasing lokasi ditarik garis utama tegak lurus dengan garis pantal sepanjang $100 \mathrm{~m}$ menuju ke arah laut. Pengamatan dilakukan dengan interval 5 meter, selain itu juga dilakukan pengamatan dengan interval 2,5 $m$ di sebelah kanan dan kiri garis transek sehingga didapatkan luas petak pengamatan $25 \mathrm{~m}$ dalam setiap intervalnya, dimana radius jangkau mata pengamat dalam observasi bawah air (English, 1994). Morfologi, tipe habitat (substrat \& kedalaman) dan jumlah total bintang laut dan bulu babi dicatat. Biota yang tidak dapat diidentifikasi di bawah air, dibawa ke laboratorium lebih lanjut diamati morfologinya (lengan, cakram pusat, madreporite, duri, mulut, kaki tabung dan alur ambulacralnya. Identifikasi jenis dilakukan dengan pedoman buku identifikasi
Clark dan Rowe (1971), Arnold dan Birtles (1989), seria Brusca dan Brusca (1990). Setelah didokumentasikan, kemudian di kembali kan ke habitatnya. Parameter lingkungan yang diukur dalam penelitian ini adalah suhu perairan, salinitas, derajat keasaman $(\mathrm{pH})$ serta kecerahan pada stasiun pengamatan sebagai data penunjang.

\section{HASIL DAN PEMBAHASAN}

Pulau cilik mempunyai dasar perairan yang landai dengan substrat dasar terdiri dan pasir, terumbu karang dan pecahan karang yang merupakan habitat bagi hewan jenis Asteroidea dan Echinoidea. Hampir seluruh pulau dikelilingi terumbu karang hingga pada kedalaman \pm 15 meter. Stasiun 1 memiliki paparan terumbu paling luas, dengan kedalaman maksimum 2 meter. Sebagian besar substrat berpasir serta pecahan karang. Prosentase tegakan karang rendah dengan dominasi karang bercabang. Stasiun 2 memiliki kondisi yang hampir sama dengan Stasiun 1, namun memiliki luas paparan terumbu yang lebih sempit. Kedalaman maksimum pada Stasiun 2 adalah 3 meter. Kondisi Stasiun 3 relatif berbeda dengan kedua stasiun lainnya. Di Stasiun 3 terdapat tubir pada jarak \pm 60 meter dari garis pantai. Kondisi habitat bervariasi dan substrat berpasir, pecahan karang hingga terumbu dengan prosentase tutupan karang cukup baik. Terdapat karang massif, namun masih didominasi oleh karang bercabang.

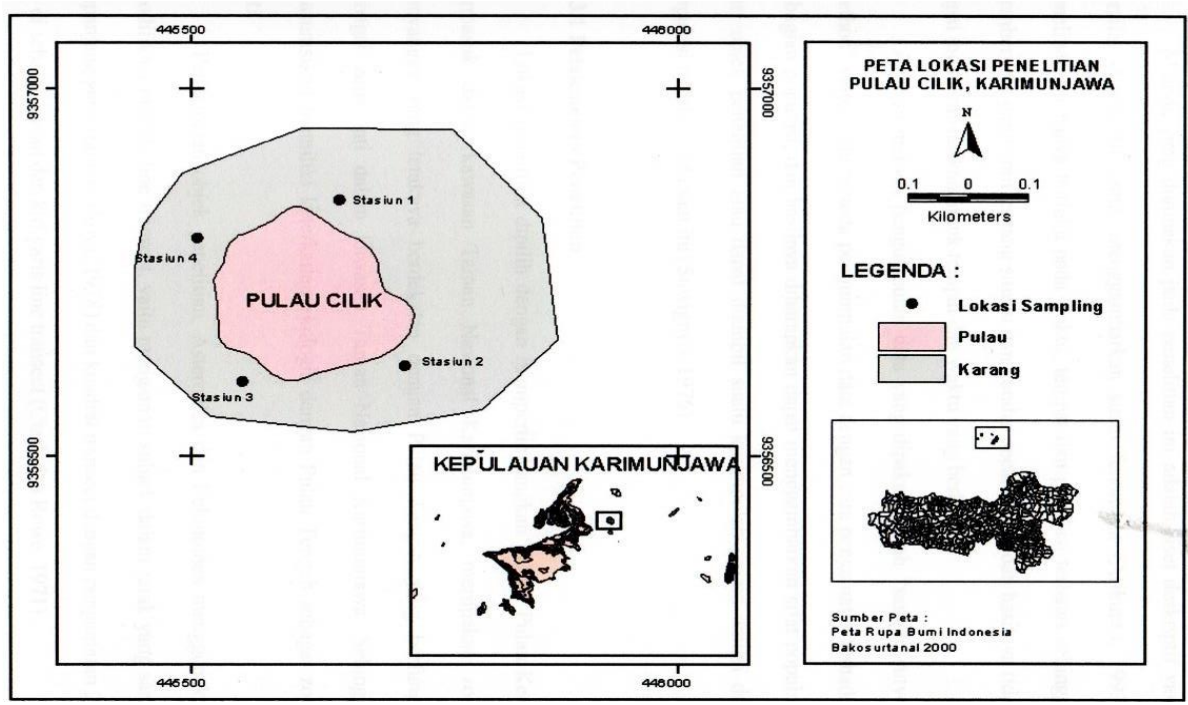

Gambar 1. Lokasi Penelitian Pulau Cilik Karimunjawa 
Kedalaman maksimum pada Stasiun 3mencapaí 20 meter. Kondisi habitat pada Stasiun 4 tak jauh berbeda dengan Stasiun 1 dan 2. Paparan bersubstrat pasir, dan pecahan karang. Penutupan karang jarang yang didominasi karang bercabang dengan kedalaman sampai 5 meter.

Hasil penelitian menunjukkan di Pulau Cilik terdapat 6 spesies Asteroidea (Bintang Laut), yaitu Acanthaster planci, Linckia laevigata, L. multifora, Luidia alternate, Culcita novaeguineae dan Neoferdifla ocellata yang termasuk dalam Famili Luidiidae, Oreasteridae, Ophidiasteridae dan Acanthasteridae. Species Echinoidea (Bulu Babi) ditemukan 4 spesies Diadema setosum, D. antillarum, D. savignyi dan Echinothrix calamaris semua anggota famili Diadematidae. Kelimpahan bintang laut dan bulu babi pada semua stasiun disajikan pada Tabel 1. Hasil pengukuran parameter kualitas prairan pada saat penelitian di Pulau Kecil disajikan dalam Tabel 2.

Kondisi Pulau Kecil yang dikelilingi terumbu karang serta karang yang cukup baik, merupakan tempat hidup yang baik bagi Echinodermata, khususnya Asteroidea dan Echinoidea. Menurut Chandra (2002), terumbu karang memberikan tempat berlindung dan penyedia pakan bagi Echinodermata. Secara ekologi biota ini berperan penting dalam ekosistem terumbu karang, umumnya sebagai grazer, predator dan pemakan detritus. Asteroidea dan Echinoidea berperan sebagai penyeimbang populasi, terutama karang, yang ada di perairan tersebut (Nybakken, 1982).

Secara umum, kondisi semua stasiun di perairan Pulau Kecil hampir sama, yaitu dikelilingi terumbu karang hingga kedalaman \pm 15 meter. Di ketiga stasiun, yaitu Stasiun 1, Stasiun 2, dan Stasiun 4 merupakan daerah paparan terumbu yang memiliki substrat dasar berpasir serta pecahan karang bercabang hingga kedalaman \pm 3 meter. Pada stasiun-stasiun tersebut, tubir berada pada jarak 100 meter atau lebih dari garis pantai. Pada Stasiun 1, daerah pasir lebih luas, sehingga jumlah spesies Asteroidea dan Echinoidea lebih sedikit atau sama, karena Asteroidea dan Echinoidea memerlukan terumbu karang sebagai tempat tinggal dan sumber makanan. Sedangkan pada stasiun paparan terumbu lebih pendek dengan tubir berada \pm 60 meter dari garis pantai, serta kedalaman hingga 20 meter. Dan pengamatan pada saat pengambilan sampel, Stasiun 3 memiliki terumbu karang hidup yang lebih baik dibanding stasiun lainnya, sehingga jumlah dan keanekaragaman biota di Stasiun 3 ini paling tinggi. Komunitas terumbu karang yang hidup di perairan Pulau Kecil cukup baik.

Pada penelitian kali ini ditemukan 6 spesies Asteroidea yang berasal dari Ordo Platyasterida, Valvatida, dan Spinulosida. Ordo Platyasterida memiliki kaki tabung tanpa penghisap (Barnes, 1980), hanya memiliki satu famili, yaitu Luidiidae. Luidiidae Sladen, 1889 merupakan famili dengan anggota species yang sedikit dari kelas Asteroidea (Kim et al., 2017). Species Luidia terdistribusi luas di perairan dangkal di subtropis dan tropis (Clark dan McKnight, 2000), dan hidup di substrat berlumpur atau berpasir. Pada saat pengambilan sampel hanya ditemukan satu spesies dari genus Luidia, yaitu L. alterna. Menurut Barnes (1980), L. alternata merupakan biota yang biasa hidup pada substrat yang lunak. Walls (1982) menyebutkan bahwa Luidia relatif mudah ditemukan pada dasar berpasir. Luidia biasanya memakan anakan kerang, namun ia juga akan makan semuanya bila mangsanya tidak bisa menyelamatkan diri. Ordo Valvatida, ditemukan dua famili (Oreasteridae dan Ophidiasteridae) dan empat genus. Family Oreasteridae meliputi Culcita, spesies C. novaeguineae. Oreasteridae umumnya memiliki cakram yang tinggi dan tebal. Lengannya sangat pendek, hingga menyerupai bentuk subpentagonal . Hampir semua spesiesnya tersebar pada perairan Indo-Pasifik barat (Arnold dan Birtles, 1989). Pada Culcita banyak sekali variasi warna yaitu merah sampai hijau dan coklat. Kwang et al. (2008) menemukan 10 pola warna (dari total 23 sampel) pada C. novaeguineae. Namun pada penelitian ini hanya ditemukan dua pola warna, yaitu merah dan abu-abu. Family Ophidiasteridae memiliki lengan yang lebih panjang, membulat seperti jari dan fleksibel. Daerah cakram lebih sempit dibanding family Oreasteridae. 
Tabel 1. Jumlah individu Asteroidea dan Echinoidea yang ditemukan di Pulau Cilik, Kepulauan Karimunjawa

\begin{tabular}{clcccc}
\hline No. Species & Stasiun 1 & Stasiun 2 & Stasiun 3 & Stasiun 4 \\
\hline & Kelas Asteroidea & & & & \\
1 & Acanthaster planci & 0 & 1 & 2 & 0 \\
2 & Linckia laevigata & 1 & 2 & 3 & 1 \\
3 & Linckia multifora & 0 & 1 & 1 & 1 \\
4 & Luidia alternate & 1 & 1 & 2 & 1 \\
5 & Culcita novaeguineae & 0 & 1 & 1 & 0 \\
6 & Neoferdifla ocellata & 0 & 0 & 1 & 1 \\
\hline$\quad$ Jumlah & 2 & 6 & 10 & 4 \\
\hline & Kelas Echinoidea & & & & 6 \\
1 & Diadema setosum & 5 & 3 & 11 & 4 \\
2 & Diadema antillarum & 3 & 6 & 9 & 2 \\
3 & Diadema savignyi & 2 & 2 & 4 & 1 \\
\hline & Echinothrix calamaris & 1 & 0 & 3 & 17 \\
\hline
\end{tabular}

Tabel 2. Parameter kualitas perairan tiap stasiun di Pulau Kecil

\begin{tabular}{lcccc}
\hline Parameter & Stasiun 1 & Stasiun 2 & Stasiun 3 & Stasiun 4 \\
\hline Suhu $\left({ }^{\circ} \mathrm{C}\right)$ & $28-30$ & $27-29$ & $28-30$ & $29-30$ \\
Salinitas $(\%$ \% & 32 & 32 & 32 & 32 \\
$\mathrm{pH}$ & $7,5-7,6$ & 7,6 & 7,5 & 7,5 \\
Kedalaman (meter) & $0-2$ & $0-3$ & $0-20$ & $0-5$ \\
DO (ppm) & 4,5 & 5,6 & 4,8 & 6,5 \\
\hline
\end{tabular}

Keberadaanya tersebar luas pada perairan dangkal di daerah tropis hingga subtropis. Ophidiasteridae memiliki wama yang sangat beragam dan umum terdapat pada terumbu karang (Arnold dan Birtles, 1989) hingga disukai para pecinta akuarium (Walls, 1982). Spesies yang ditemukan pada saat pengambilan sampel antara lain L. laevigata, L. multifora, dan N. ocellata. Pada penelitiannya di kawasan terumbu karang di Laut China Selatan (Kwang et al., 2008) menemukan dua variasi warna dari Bintang Laut L. multifora, yaitu warna yang umum (kulit keputihan dengan spot-spot merah) serta pola yang jarang ada yaitu kulit berwarna abu-abu dengan spot-spot ungu tua. Pada penelitian ini L. multifora mempunyai spot-spot kemerahan pada kulit yang keputihan.

Satu spesies ditemukan termasuk ordo Spinulosida dari famili Acanthasteridae, yaitu A. planci. Ordo Spinulosida mempunyai ciri yang hampir sama dengan ordo Valvatida.
Yang membedakan adalah kaki tabung Spinulosida memiliki penghisap, sedangkan Valvatida tidak memiliki penghisap, serta cakram marginal pada Spinulosida tidak menyolok seperti pada Valvatida (Barnes, 1980; Arnold dan Birtles, 1989). Spesies Asteroidea yang perlu diwaspadai adalah ditemukannya $A$. planci ini karena $A$. planci mengkonsumsi polip karang sebagai makanannya. Dalam satu hari setidaknya ia akan makan karang sebanyak ukuran cakramnya. Nybakken (1982) melaporkan bahwa Acanthaster dapat mengurangi karang yang tumbuh cepat dan menolong spesies yang tumbuh lambat agar dapat terjamin kelangsungan hidupnya, namun bila terjadi ledakan populasi, seluruh terumbu akan dirusak dan hampir semua karang dimakan. Jenis Asteroidea lainnya kebanyakan merupakan suspension feeder.

Kelimpahan tertinggi dari kelas Asteroidea, adalah spesies L. laevigata dengan 7 individu, kemudian L. alternata 
dengan 5 indvidu, A. planci dan L. multifora 3 indv., dan yang paling sedikit adalah $C$. novaeguineae dan N. Ocellata. Semua jenis Asteroidea ditemukan di Stasiun 3 dan hanya 3 spesies di Stasiun 1. Stasiun 3 merupakan perairan dengan paparan terumbu dan tubir. Daerah rataan terumbu dan tubir merupakan daerah yang paling disukal oleh Asteroidea karena daerah ini merupakan daerah yang kaya akan sumber makanan.

Spesies yang paling banyak ditemukan dari kelas Asteroidea adalah dari ordo Valvatida, family Ophidiasteridae, dan spesies yang paling banyak adalah Linckia laevigata. Hal ini diduga karena kemampuanya yang luar biasa dalam beregenerasi. Kwang et al. (2008) menyatakan bahwa Linckia dapat melepaskan lengannya sampai dekat dengan cakram tengah (central disc). Bagian utama maupun lengan yang lepas dapat beregenerasi membentuk bagian yang hilang, hingga pada akhirnya terbentuk satu individu baru yang utuh.

Empat spesies Echinoidea ditemukan pada penelitian ini, yang kesemuanya berasal dari ordo Diadematoida. Diadema merupakan regular urchin, umumnya memiliki duri yang panjang, berlubang, cangkang ada yang kaku dan ada yang fleksibel (Barnes, 1980; Arnold dan Birtles, 1989). Secara keseluruhan Echinoidea yang paling banyak ditemukan berturut-turut adalah $D$. setosum (25 indv.), D. antillarum (22 indv.), D. savignyi (10 indv.) dan Echinothrix calamaris (5 indv.). Ketiga species bulu babi genus Diadema ditemukan disemua stasiun dan $E$. calamaris tidak ditemukan di Stasiun 2. D. setosum menyebar hampir di semua habitat baik pada daerah rataan pasir, karang, lamun dan daerah tubir seperti pada penelitian Dominggus et al. (2008).

Hadi et al. (2011) di Indonoor Wreck, Pulau Kemujan mendapatkan L. laevigata, Fromia nomilis, A. planci dan C. novaguinae (Asteroidea) dan D. setosum, D. Savignyi, Echinometra mathei dan E. calamaris. Menurut Iken et al. (2010) sebagai habitat, terumbu karang berperan sebagai penyedia bahan pakan dan tempat berlindung bagi fauna echinodermata dan sebaliknya fauna echinodermata berfungsi pendaur-ulang nutrien, yaitu sebagai pemakan detritus yang pada gilirannya akan bermanfaat bagi terumbu karang (Sastry, 2001).

Jumlah individu Asteroidea yang ditemukan pada penelitian kali ini lebih sedikit dibanding dengan Echinoidea. Hal ini diduga karena adanya predasi yang memangsa Asteroidea dan Echinoidea. Dalam Romimohtarto dan Juwana (1999) disebutkan bahwa pemangsa utama $A$. planci adalah Charonia tritons (Giant Triton). Perbedaan kelimpahan tersebut juga diduga berhubungan dengan life habit, terutama pada fase juvenil. Juvenil Echinoidea biasa berlindung di bawah batu, karang, padang lamun serta di dekat induknya sehingga terlindungi oleh duri-duri induknya (Barnes, 1980). Jumlah individu Asteroidea dan Echinoidea yang sedikit ditemukan diduga juga disebabkan oleh kebiasaan makan dan biota tersebut. Asteroidea merupakan biota yang aktif di siang hari. Beberapa Asteroidea mengambil makanan pada pagi dan sore hari (Hyman, 1955). Sedangkan Echinoidea aktif mencari makan pada malam hari, dan pada siang hari kembali ke daerah terumbu (Barnes, 1980). Pengambilan sampel pada waktu penelitian dilakukan pada pagi hari sehingga banyak ditemukan Asteroidea dan Echinoidea di daerah terumbu karang.

Manusia juga diduga berperan dalam mengurangi kelimpahan Asteroidea dan Echinoidea, karena banyak diambil hidup maupun mati untuk Akuarium, atau hiasan Emmens, 1990). Sedangkan Echinodea diambil untuk dikonsumsi gonadnya di beberapa negara (Longhurst dan Pauly, 1987), seperti negara-negara Mediteran, juga Hindia Barat (Walls, 1982). Namun di Indonesia gonad Bulu Babi belum banyak dikonsumsi, sehingga keberadaannya belum banyak tereksploitasi. Keberadaan Echinoidea sangat penting dalam ekosistem terumbu karang. Seperti penelitian yang dilakukan oleh Sammarco, Levinton dan Ogden (1974) dalam Nybakken (1982) memperlihatkan bahwa Diadema pada kepadatan tinggi akan memakan semua organisme, tidak hanya alga, sehingga akan menghalangi pertumbuhan karang. Pada kepadatan yang lebih rendah, bulu babi secara efektif memindahkan alga dan 
membiarkan koloni karang berkembang, sedangkan pada kepadatan yang sangat rendah, alga mengambil alih daerah itu dengan memerangi karang karena tidak adanya grazing. Dengan demikian secara tidak langsung, Echinoidea membantu pemeliharaan terumbu karang.

Pada penelitian di Pulau Cilik Karimunjawa hanya ditemukan 6 species Bintang Laut, yang jauh lebih sedikit dibandingkan dengan penelitian Purwati \& Lane (2004) yang mengidentifikasi 27 species bintang laut dari 9 famili; juga lebih sedikit daripada di Perairan Likupang, Minahasa Utara (Yusron, 2010) dan di Selat Lembeh, Sulawesi Utrara (Supono et al., 2014) dan perairan Pulau Tomia, Taman Nasional Wakatobi, Sulawesi Tenggara (Analuddin et al., 2015). Secara umum jumlah jenis Asteroidea dan Echinoidea di Pulau Cilik ini lebih banyak daripada di kawasan lamun dan makroalga perairan Tanjung Kayangan, Penyabuan dan Medana Lombok (Yusron, 2013) dan Pulau Tanakeke, Kabupaten Takalar, Sulawesi Selatan (Angreni et al., 2017) dan di perairan Tanjung Tiram, Teluk Ambon (Tuapattinaja et al., 2014) sehingga perbedaan habitat diduga membedakan hasil tersebut. Dibandingkan dengan penelitian Tahe et al. (2013) hasil ini hampir sama dengan yang ditemukannya di Pantai Tanamon Kecamatan Sinonsayang Sulawesi Utara.

Pada saat penelitian tidak ditemukan Dolar Pasir (Sand Dollar) seperti di Pulau Cemara Besar (Dian et al., 2005) dan Pulau Cemara Kecil (Mu'arif, 2009; Suryanti et al., 2016; Asmoro et al., 2017) atau Bulu Hati (Heart Urchin). Hal ini diduga karena kebiasaan Sand Dollar serta Heart Urchin yang membenamkan dirinya dalam substrat dasar. Dikatakan oleh Barnes (1980) bahwa Echinoidea irregular beradaptasi untuk hidup membenam dalam pasir. Kebiasaan membenamkan diri tersebut berkaitan dengan pertahanan diri baik dari arus yang kuat maupun dari pemangsaan.

\section{KESIMPULAN}

Pulau Cilik di Kepulauan Karimunjawa mempunyai dasar perairan yang landai dengan substrat dasar terdiri dan pasir, terumbu karang dan pecahan karang yang merupakan habitat bagi hewan jenis Asteroidea dan Echinoidea. Di perairan tersebut ditemukan enam spesies Asteroidea (Bintang Laut), yaitu Linckia laevigata, L. multifora, Neoferdifla ocellata (Famili Ophidiasteridae), Luidia alternate (Famili Luidiidae), Culcita novaeguineae (Famili Oreasteridae) dan Acanthaster planci yang termasuk dalam Famili Acanthasteridae. Species Echinoidea (Bulu Babi) ditemukan 4 spesies Diadema setosum, D. antillarum, D. savignyi dan Echinothrix calamaris semua anggota famili Diadematidae.

\section{DAFTAR PUSTAKA}

Alvarado, J.J., Guzman, H.M., \& Breedy, O. 2012. Distribution and diversity of echinoderms (Asteroidea, Echinoidea, Holothuroidea) in the islands of the Gulf of Chiriqui, Panama. Revista de Biolog. Mar. Oceano. 47(1):13-22.

Analuddin, K., Nasaruddin, N., Septiana, A., Sarliyana, W. O., Nurlyati, A., Masa, W., \& Rahim, S. 2015. Spatial Pattern in Beta Diversity of Echinoidea and Asteroidea Communities from the Coastal Area of Tomia Island, Wakatobi Marine National Park, Southeast Sulawesi, Indonesia. Biotropia. 22(1):33- 43

Angreni, F., Litaay, M., Priosambodo, D. \& Moka, W. 2017. Struktur Komunitas Echinodermata Di Padang Lamun Pulau Tanakeke Kabupaten Takalar Sulawesi Selatan. Bioma: J. Biol. Makassar. 2(1):4655

Arm, K. \& Camp, P.S. 1997. Biology. Saunders College Pub. USA. 1142p.

Arnold, P.W. \& Birtles, R.A. 1989. Soft sediment invertebrates of Southeast Asia and Australia: A Guide to identification. Australian Institute of Marine Science. Townsville. 236p.

Asmoro, C.L., Suryanti, \& 'Ain, C. 2017. Hubungan Kandungan Bahan Organik Sedimen Dengan Kelimpahan Sand Dollar Di Pulau Cemara Kecil Karimunjawa Jepara. Prosiding Seminar Nasional Hasil-Hasil Penelitian Perikanan dan Kelautan ke-VI. Fakultas Perikanan dan IImu Kelautan - Pusat Kajian Mitigasi Bencana dan Rehabilitasi Pesisir, Undip. Pp. 287-300. 
Azis, A. \& Darsono, P. 1999. Fauna echinodermata dari Pulau-pulau Karimunjawa. IImu Kelautan. 14(IV):83-87

Barnes, R.S.K. 1980. Invertebrates zoology. Saunders College Pub. USA. 1089p.

Bellwood, D.R., Hughes, T.P., Folke, C., \& Nyström, M. 2004. Confronting the coral reef crisis. Nature. 429(6994): 827-833.

Birkeland, C. \& Lucas, J.C. 1989. Acanthaster planci: Major management problems of coral reefs. CRC Press Inc. USA. 257 p.

Brusca, R.C. \& G.J. Brusca. 1990. Invertebrates. Sinaver Asssociates Inc. Pb. USA. P:801-839

Chenelot, H., Iken, K., Konar, B., \& Edwards, M. 2007. Spatial and Temporal Distribution of Echinoderms in Rocky Nearshore Areas of Alaska. The Nagisa World Congress: 1128.

Clark, A.M. \& F.W.F. Rowe. 1971. Monograph of Shallow Water Indowest Pasific Echinoderms. London. 269p.

Clark, H.E.S., \& McKnight D.G., 2000. The marine fauna of New Zealand: Echinodermata: Asteroidea (sea-stars), Order Paxillosida. National Institute of Water and Atmospheric Research (NIWA) Biodiversity Memoires, 1 16:14-135

Dian A.R, Hartati, R. \& Ambariyanto, A. 2005. Identifikasi Sand Dollar dan Karakteristik Habitatnya di Pulau Cemara Besar, Kepulauan Karimunjawa Jepara. Ilmu Kelautan. 10(1):1-10. DOI: https://doi.org/ 10.14710/ik.ijms.10.1.1-10

Emmens, C.W. 1990. Marine aquaria and miniature reef, the fishes, the invertebrates, the techniques. TFH Pub. Inc. USA. 317p

Iken, K., Konar, B., Benedetti-Cecchi, L., CruzMotta, J.J., \& Knowlton, A. 2010. LargeScale Spatial Distribution Patterns of Echinoderms in Nearshore Rocky Habitats. PLOS ONE 5(11):e13845. DOI : 10.1371/journal.pone.0013845

Kim, D., Kim, M. and Shin, S., 2017. A Newly Recorded Sea Star of the Genus Luidia (Asteroidea: Paxillosida: Luidiidae) from the Korea Strait, Korea. Anim. Syst. Evol. Divers. 33(2): 131-135. DOI : 10.5635/AS ED.2017.33.2.061

Kwang, S.Y., Shau-Hwai, A.T. \& Yasin, Z. 2008. The Diversity and Abundance of the Sea Stars (Echinodermata: Asteroidea) from Coral Reefs of the Central South China
Sea. The Nagisa Westpac Congress: 2536.

Longhurst, A.R. \& D. Pauly. 1987. Ecology of tropical oceans. Academic Press Inc. USA.

Mah, C.L. \& Blake, D.B. 2012. Global Diversity and Phylogeny of the Asteroidea (Echinodermata). PLoS ONE 7(4): e35644. DOI : 10.1371/journal.pone.0035644

Mu'arif. 2009. Kelimpahan Dan Distribusi Sand dollar (Laganum Sp) Pada Substrat Dasar Yang Berbeda Di Pulau Cemara Kecil Kepulauan Karimunjawa Jepara. Undip. Semarang.

Nybakken, J.W. 1992. Biologi Laut: Suatu pendekatan ekologis. Penerbit PT. Gramedia. Jakarta. 456 hal.

Purwati, P. \& Lane, D.J.W. 2004. Asteroidea of the Anambas expedition 2002. The Raffles Bull. Zool. 11:89-102

Romimohtarto, K. \& Juwana, S. 1999. Biologi Laut. P3O LIPI. Jakarta. 648 hal.

Supono, D.J., Lane, W. \& Susetiono. 2014. Echinoderm Fauna Of The Lembeh Strait, North Sulawesi: Inventory And Distibution Review. Mar. Res. Ind. 39(2): 51-61

Suryanti, Muskananfola, M.R. \& Simanjuntak, K.E., 2016. Sand Dollars Distribution Pattern And Abundance At The Coast Of Cemara Kecil Island, Karimunjawa, Jepara, Indonesia. Jurnal Teknologi, 78(42):239-244 .

Tahe, O.S., Langoy, M.L.D., Katili, D.Y. \& Papu, A. 2013. Keanekaragaman Echinodermata di Pantai Tanamon Kecamatan Sinonsayang Sulawesi Utara. J. Bios. Logos 3(2):65-72

Tuapattinaja, M.A., Pattikawa, J.A. \& Natan. Y. 2014. Community structure of Echinoderms at Tanjung Tiram, inner Ambon bay, Indonesia. AACL Bioflux 7(5): 351-356.

Walls, J.G. 1982. Encyclopedia of Invertebrates. TFH Pb. Inc. Ltd. England.

Yusron, E. 2010. Keanekaragaman Jenis Ekhinodermata di Perairan Likupang, Minahasa Utara, Sulawesi Utara. IImu Kelautan. 15(2):85-90

Yusron, E. 2013. Biodiversitas Fauna Ekhinodermata (Holothuroidea, Echinoidea, Asteroidea dan Ophiuroidea) di Perairan Pulau Lombok, Nusa Tenggara Barat. Zoo Ind. 22(1):1-10 